(๑ С. Г. Абрамович, В. А. Дробышев, 2017

УДК 616.83:621.398

DOI - https://doi.org/10.14300/mnnc.2017.12057

ISSN - 2073-8137

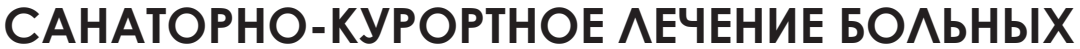 АРТЕРИААЬНОЙ ГИПЕРТОНИЕЙ: ВЫБОР ТАКТИКИ С ПОМОЩЬЮ МАТЕМАТИЧЕСКОГО МОАЕАИРОВАНИЯ
}

\author{
С. Г. Абрамович ${ }^{1}$, В. А. Аробышев ${ }^{2}$ \\ ${ }^{1}$ Иркутская госуаарственная МеАицинская академия \\ ПослеАИП^ОМноГО Образования, РосСия \\ 2 Новосибирский госуАарственный меАицинский университет, Россия
}

\section{SANATORIUM-SPA TREATMENT OF PATIENTS WITH ARTERIAL HYPERTENSION: SELECTION OF TACTICS BY MATHEMATICAL MODELING}

\author{
Abramovich S. G. ', Drobyshev V. A. ${ }^{2}$ \\ ${ }^{1}$ Irkutsk State Medical Academy of Postgraduate Education, Russia \\ 2 Novosibirsk State Medical University, Russia
}

\begin{abstract}
Реализовано обоснование актуальности использования математического моделирования при выборе методики санаторно-курортного лечения. Количество больных, принявших участие в исследовании, со-

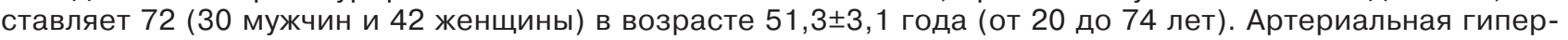
тония наблюдалась в 1-2 стадии, 1 степени, низкого, среднего и высокого риска развития осложнений. Дифференцированы результаты терапии вследствие выбора тактики лечения в санаторно-курортном комплексе.

Лучшие результаты были показаны по гемодинамическим показателям, выраженности клинических проявлений заболевания, а также по параметрам качества жизни тех пациентов, которым лечение назначалось с помощью математического моделирования. Проведенное в санаторно-курортном комплексе лечение повышает качество жизни пациентов за счет воздействия на физический компонент здоровья.

Планирование курортной терапии с учетом принципов математического моделирования позволяет более точно определить тактику санаторного лечения.
\end{abstract}

Ключевые слова: артериальная гипертония, математическое моделирование, выбор лечения

The article substantiates the relevance of the use of mathematical modeling in choosing the method of sanatorium treatment. The number of patients who participated in the study is 72 ( 30 men and 42 women) aged $51.3 \pm 3.1$ years (from 20 to 74 years). Arterial hypertension was observed in 1-2 stages, 1st degree, low, medium and high risk of complications. The results of therapy are differentiated due to the choice of treatment tactics in the sanatorium complex.

The best results were shown by hemodynamic parameters, the severity of clinical manifestations of the disease, and also by the parameters of the quality of life of those patients to whom treatment was prescribed using mathematical modeling. The treatment carried out in the sanatorium complex improves the quality of life of patients by influencing the physical component of health.

Planning spa therapy, taking into account the principles of mathematical modeling allows to determine more accurately the tactics of sanatorium treatment.

Keywords: hypertension, mathematical modeling, choice of treatment

H есмотря на достижения современной антигипертензивной фармакологии, частота распространения артериальной гипертонии (АГ) в мире сохраняется высокой [7]. Это обстоятельство требует новых подходов к профилактике и лечению, в том числе в санаторно-курортных условиях, где ведущая роль принадлежит природ- ным и преформированным лечебным физическим факторам [5].

Санаторно-курортное лечение (СКЛ) у больных АГ не только способствует формированию здорового образа жизни, позитивно изменяет существующие у пациентов факторы риска, но и оказывает влияние на ключевые патогенетические механизмы развития за- 
болевания [5]. Результаты немногочисленных исследований показывают целесообразность использования при АГ бальнеотерапии хлоридными натриевыми ваннами (XHMB) в виде монотерапии, в комплексах с общей (OMT) или трансцеребральной магнитотерапией (ТМ), однако отсутствуют работы, в которых изучалась возможность применения «интенсивного» курортного лечения, когда используется бальнеотерапия и комбинированные методики магнитотерапии $[1,3]$.

Тактика лечения физическими факторами АГ при СКЛ строится на общепринятых стандартизированных подходах, при которых выбор метода физиотерапии в значительной степени основывается на субъективной оценке врачом состояния пациента. Однако нозологическая диагностика не в состоянии предоставить достаточную информацию для реализации системного подхода к выбору наиболее эффективного метода лечения. Существующие стандартные схемы СКЛ не предусматривают достаточной результативности при наличии сопутствующей патологии, различной индивидуальной чувствительности к физическим факторам. Не разработаны независимые интегральные параметры-предикторы, обладающие прогностической информативностью, не проводилось исследований, в которых изучались вопросы выбора тактики СКЛ с использованием приемов математического моделирования.

Целью работы был сравнительный анализ стандартизированного подхода и математического моделирования в выборе тактики санаторно-курортного лечения у больных артериальной гипертонией.

Материал и методы. Исследование носит характер проспективного, рандомизированного. Количество больных составило 72 человека (30 мужчин и 42 женщины) в возрасте 51,3 33,1 года (возрастной интервал от 20 до 74 лет). У всех обследованных имела место 1 и 2 стадии АГ, 1 степень, низкий, средний и высокий риск развития осложнений. Стаж заболевания составлял от 4 до 22 лет. Базой лечения являлся Ангарский санаторий-профилакторий «Родник».

Диагноз был верифицирован в соответствии с Российскими клиническими рекомендациями по диагностике и лечению АГ $[8,9]$.

Критерии включения: наличие верифицированного диагноза АГ 1 и 2 стадии, 1 степени с низкой, средней и высокой степенью риска осложнений. Критерии исключения: общие противопоказания для назначения бальнеологического лечения и магнитотерапии, симптоматическая АГ, хроническая сердечная недостаточность выше 1 стадии и 1 функционального класса (NYHA), острое нарушение мозгового кровообращения в анамнезе, дисциркуляторная энцефалопатия выше 1 стадии, ишемическая болезнь сердца и другие органические заболевания сердечно-сосудистой системы, нежелание пациента принимать участие в исследовании и несоблюдение программы графика лечения и обследования.

При поступлении в санаторий больным проводилось обследование, по результатам которого были сформированы две группы, сопоставимые по основным клиническим проявлениям и коморбидной патологии. Контрольное обследование проводилось на 20-й день.

Первая группа пациентов состояла из 45 человек (25 женщин, 20 мужчин), которым разработанный нами лечебный комплекс был назначен с использованием формул математического моделирования и линейных дискриминантных функций [3, 4]. Представителям второй группы (сравнения) в количестве
27 человек (17 женщин, 10 мужчин) аналогичное СКЛ было рекомендовано в соответствии с существующими стандартными подходами, учетом показаний и противопоказаний.

Качество жизни (КЖ) определялось с помощью опросника «SF-36 Status Survey». Анкета включала 36 вопросов, разделенных на 8 шкал: общее состояние здоровья (GH), физическое функционирование (PF), ролевое физическое функционирование (RP), телесная боль (BP), жизненная активность (VT), социальное функционирование (SF), ролевое эмоциональное функционирование (RE) и самооценка психического здоровья (МН). Расчеты позволяют представить значения каждой категории КЖ от 0 до 100 отн. ед., более высокая оценка указывает на более высокий уровень КЖ. Показатели GH, PF, RP и ВP составляют физический компонент здоровья (ФКЗ), шкалы VT, SF, RE и MH характеризуют психологический компонент (ПКЗ).

В качестве интегрального показателя был разработан медицинский параметр качества жизни (МПКЖ) [2]. В анкету, которая предназначалась для изучения клинических проявлений у больных АГ, вносились 18 симптомов. Больной самостоятельно отмечал наличие и выраженность симптомов. Ответ оценивался в баллах, сумма которых определяла МПКЖ.

Определялись частота сердечных сокращений (ЧСС), артериальное давление (АД), индекс работы сердца (ИРС). Производили расчет среднегемодинамического АД (АД $\mathrm{cp})$, минутного объёма сердца (МОC), ударного объёма сердца (УОС), общего периферического сосудистого сопротивления (ОПСС).

Пациенты обеих групп на курорте получали идентичный комплекс лечения, включающий диетотерапию, лечебную физкультуру, плавание в бассейне, сеансы психотерапии, бальнеотерапию ХНМВ и процедуры комплексной магнитотерапии.

Представители обеих групп получали равноценную терапию лекарственными средствами. Комплекс лечебных процедур составлялся с учетом хронобиологических ритмов.

Для проведения статистической обработки материала использовали пакеты прикладных программ «Statistica 6.1» («Statsoft», США). Для оценки нормальности распределения данных использовали визуально-графический метод и критерии согласия Колмогорова - Смирнова с поправкой Лиллиефорса и Шапиро - Уилка. В нашем исследовании определение в выборках имело статистически значимое отличие от нормального, поэтому данные представляли в виде «среднее \pm стандартное отклонение» (M+SD), а также в процентах. Для определения значимости отличий применялся непараметрический U-критерий Манна - Уитни для сравнения двух независимых выборок. Критический уровень значимости при проверке статистических гипотез в исследовании принимался равным 0,05. Для построения математической модели выбора тактики санаторно-курортного лечения был использован многофакторный дискриминантный анализ. Для кластеризации данных использовали метод к-средних, с проверкой точности разделения групп дискриминантным анализом [6].

Результаты исследования. При разработке математической модели выбора тактики СКЛ был создан алгоритм методологии персонализированного подхода, включающий несколько этапов [4]. На первом этапе разрабатывалась формализованная история болезни, клинические и функциональные показатели были закодированы, количественные их значения представлялись в натуральных единицах из- 
мерения или баллах. Доказательная база была представлена 57 клинико-функциональными показателями, характеризующими антропометрические данные, выраженность клинических проявлений заболевания, психологический статус, параметры качества жизни, состояние терморегуляции и термореактивности, параметры центральной гемодинамики.

Второй этап предусматривал оценку информативности изучаемых параметров, отбор наиболее значимых признаков, а также получение решающих правил в виде линейных классификационных дискриминантных функций. Их анализ определил 4 ведущих показателя, характеризующих функциональное состояние сердечно-сосудистой системы: среднее систолическое АД в дневное время (САДд), АД чСС и центральное пульсовое АД. Определенным показателям присваивались градации, а также значения функций, по величине которых пациентам был рекомендован конкретный метод лечения [4].

На третьем этапе мы определили правильность выбора тактики комплексного СКЛ у больных АГ, который был осуществлен двумя способами: с помощью классического стандартизированного подхода и предложенных нами приемов математического моделирования [3]. Полученные данные показали, что выбор тактики СКЛ у больных АГ оказывает существенное значение на его медицинскую результативность. При анализе основных параметров качества жизни, характеризующих субъективную составляющую эффективности лечебных мероприятий, как правило, у пациентов сравниваемых групп наблюдалась однонаправленность сдвигов (табл. 1). Различия, в основном, носили количественный характер. Так, до лечения величина МПКЖ у больных

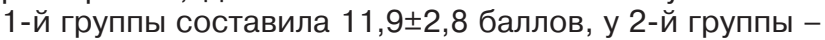
$12,0 \pm 3,1$ баллов, соответственно после лечения отмечено снижение на 29,4\% $(8,4 \pm 3,0$ баллов; $p<0,001)$ и

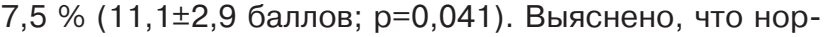
мализация клинических проявлений у представителей 2-й группы и, в большей степени, у пациентов 1-й группы происходила за счет уменьшения характера и выраженности такой симптоматики, как головные боли, головокружение, ощущение тяжести в голове, утомляемость, раздражительность, плаксивость, кардиалгии, снижение работоспособности и памяти.

Сравнительный анализ выбора тактики СКЛ в виде математического моделирования и стандартизированного подхода по шкалам SF-36 показал, что в первом случае курортная терапия способствовала повышению показателей, характеризующих физический компонент здоровья. Так, у больных 1-й группь после лечения имело место увеличение общего состояния здоровья (на $8,5 \%$; $\mathrm{p}=0,021)$, физического функционирования (на 18,2\%; $<<0,001$ ), ролевого физического функционирования (на $34,5 \%$; $\mathrm{p}<0,001$ ) и телесной боли (на 16,6 \%; $\mathrm{p}<0,001)$. Динамика аналогичных параметров в сравниваемой группе показала значительно меньший прирост, а достоверность наблюдалась только у показателей физического функционирования
Таблица 1

Показатели уровня жизни больных артериальной гипертонией в зависимости от способа выбора тактики санаторно-курортного лечения (M $\pm \mathrm{SD}$ )

\begin{tabular}{|c|c|c|c|c|c|c|}
\hline $\begin{array}{c}\text { Пока- } \\
\text { затель }\end{array}$ & $\begin{array}{c}\text { Математическое } \\
\text { моделирование } \\
\text { (1 группа) }\end{array}$ & $\begin{array}{c}\text { Стандартный } \\
\text { подход } \\
\text { (2 группа) }\end{array}$ & $\begin{array}{c}p \\
(1 \text { груп- } \\
\text { па) }\end{array}$ & $\begin{array}{c}p \\
(2 \text { груп- } \\
\text { па) }\end{array}$ & $\begin{array}{c}\Delta \% \\
(1 \text { груп- } \\
\text { па) }\end{array}$ & $\begin{array}{c}\Delta \% \\
(2 \text { груп- } \\
\text { па) }\end{array}$ \\
\hline $\begin{array}{l}\text { МПКЖ, } \\
\text { баллыы }\end{array}$ & $\frac{11,9( \pm 2,8)}{8,4( \pm 3,0)}$ & $\frac{12,0( \pm 3,1)}{11,1( \pm 2,9)}$ & $<0,001$ & 0,041 & $-29,4$ & $-7,5$ \\
\hline $\begin{array}{l}\mathrm{GH}, \\
\text { отн. ед. }\end{array}$ & $\frac{55,6( \pm 4,6)}{60,3( \pm 3,9)}$ & $\begin{array}{l}\frac{53,7( \pm 4,4)}{52,6( \pm 3,2)} \\
\end{array}$ & 0,021 & $>0,05$ & $+8,5$ & $-2,1$ \\
\hline $\begin{array}{l}\text { PF, } \\
\text { отн. ед. }\end{array}$ & $\frac{62,5( \pm 3,2)}{73,9( \pm 3,0)}$ & $\frac{61,9( \pm 3,3)}{66,4( \pm 2,9)}$ & $<0,001$ & 0,032 & $+18,2$ & $+7,3$ \\
\hline $\begin{array}{l}\text { RP, } \\
\text { отн. ед. }\end{array}$ & $\frac{44,7( \pm 3,4)}{60,1( \pm 3,7)}$ & $\frac{52,1( \pm 4,0)}{54,6( \pm 3,8)}$ & $<0,001$ & $>0,05$ & $+34,5$ & $+4,8$ \\
\hline $\begin{array}{l}\text { BР, } \\
\text { отн. ед. }\end{array}$ & $\frac{50,0( \pm 3,1)}{58,3( \pm 4,0)}$ & $\frac{49,8( \pm 3,8)}{56,4( \pm 3,9)}$ & $<0,001$ & 0,009 & $+16,6$ & $+13,3$ \\
\hline $\begin{array}{l}\text { VT, } \\
\text { отн. ед. }\end{array}$ & $\frac{46,0( \pm 4,1)}{47,5( \pm 3,8)}$ & $\begin{array}{l}48,1( \pm 5,0) \\
48,0( \pm 4,4)\end{array}$ & $>0,05$ & $>0,05$ & $+3,3$ & $-0,2$ \\
\hline $\begin{array}{l}\text { SF, } \\
\text { отн. ед. }\end{array}$ & $\frac{48,8( \pm 3,6)}{50,2( \pm 3,4)}$ & $\frac{50,1( \pm 4,0)}{50,2( \pm 3,7)}$ & $>0,05$ & $>0,05$ & $+2,9$ & $+1,9$ \\
\hline $\begin{array}{l}\mathrm{RE}, \\
\text { отн. ед. }\end{array}$ & $\frac{60,0( \pm 4,3)}{65,7( \pm 4,0)}$ & $\frac{58,1( \pm 3,9)}{60,4( \pm 4,2)}$ & 0,007 & $>0,05$ & $+9,5$ & $+3,9$ \\
\hline $\begin{array}{l}\text { МН, } \\
\text { отн. ед. }\end{array}$ & $\begin{array}{l}59,7( \pm 2,9) \\
60,8( \pm 3,1)\end{array}$ & $\frac{60,8( \pm 3,0)}{62,0( \pm 3,4)}$ & $>0,05$ & $>0,05$ & $+1,8$ & $+2,0$ \\
\hline $\begin{array}{l}\text { ФКЗ, } \\
\text { отн. ед. }\end{array}$ & $\frac{50,1( \pm 3,3)}{58,5( \pm 4,0)}$ & $\frac{48,7( \pm 3,6)}{50,9( \pm 3,8)}$ & $<0,001$ & $>0,05$ & $+16,8$ & $+4,5$ \\
\hline $\begin{array}{l}\text { ПКЗ, } \\
\text { отН. ед. }\end{array}$ & $\frac{51,4( \pm 3,2)}{53,5( \pm 3,5)}$ & $\frac{52,7( \pm 3,0)}{54,0( \pm 3,4)}$ & $>0,05$ & $>0,05$ & $+4,1$ & $+2,5$ \\
\hline
\end{tabular}

Примечание: здесь и в таблице $2 \Delta t$ (\%) - внутригрупповая разница между показателями до и после лечения; числитель - показатель до лечения, знаменатель - после лечения; p - внутригрупповой критерий значимости различий до и после лечения.

и телесной боли соответственно на 7,3\% $(p=0,032)$ и 13,3 \% ( $p=0,009)$. Среди показателей, характеризующих психологическое здоровье, достоверность имела место только у пациентов 1-й группы по шкале «ролевое эмоциональное функционирование» в виде увеличения на $9,5 \%(p=0,007)$.

Анализ гемодинамических показателей показал, что СКЛ наиболее эффективно у пациентов, выбор лечения которых обусловлен математическим моделированием (табл. 2).

Таблица 2

Показатели гемодинамики больных артериальной гипертонией в зависимости от тактики санаторно-курортного лечения (M+SD)

\begin{tabular}{|l|c|c|c|c|c|c|}
\hline \multicolumn{1}{|c|}{$\begin{array}{c}\text { Пока- } \\
\text { затель }\end{array}$} & $\begin{array}{c}\text { Математическое } \\
\text { моделирование } \\
(1 \text { группа) }\end{array}$ & $\begin{array}{c}\text { Стандартный } \\
\text { подход } \\
(2 \text { группа) }\end{array}$ & $\begin{array}{c}p \\
(1 \text { груп- } \\
\text { па })\end{array}$ & $\begin{array}{c}p \\
(2 \text { груп- } \\
\text { па) }\end{array}$ & $\begin{array}{c}\Delta \% \\
(1 \text { груп- } \\
\text { па }\end{array}$ & $\begin{array}{c}\Delta \% \\
(2 \text { груп- } \\
\text { па })\end{array}$ \\
\hline $\begin{array}{l}\text { чСС, уд. } \\
\text { В 1 мин }\end{array}$ & $\frac{70,0( \pm 1,6)}{68,1( \pm 1,8)}$ & $\frac{68,9( \pm 2,0)}{68,0( \pm 1,7)}$ & $>0,05$ & $>0,05$ & $-2,7$ & $-1,3$ \\
\hline $\begin{array}{l}\text { АД систоли- } \\
\text { ческое, } \\
\text { мм рт. ст. }\end{array}$ & $\frac{142,4( \pm 11,6)}{129,7( \pm 10,1)}$ & $\frac{139,8( \pm 12,3)}{133,6( \pm 10,2)}$ & $\mathbf{0 , 0 0 9}$ & $>0,05$ & $-8,9$ & $-4,4$ \\
\hline $\begin{array}{l}\text { АД диасто- } \\
\text { лическое, } \\
\text { мм рт. ст. }\end{array}$ & $\frac{90,4( \pm 8,0)}{82,6( \pm 7,3)}$ & $\frac{91,1( \pm 7,8)}{86,9( \pm 6,1)}$ & $\mathbf{0 , 0 2 5}$ & $>0,05$ & $-8,6$ & $-4,6$ \\
\hline $\begin{array}{l}\text { АД средне- } \\
\text { гемодина- } \\
\text { мическое, } \\
\text { мм рт. ст. }\end{array}$ & $\frac{107,7( \pm 5,9)}{98,3( \pm 5,1)}$ & $\frac{107,3( \pm 6,2)}{102,5( \pm 5,8)}$ & $\mathbf{0 , 0 4 6}$ & $>0,05$ & $-8,7$ & $-4,5$ \\
\hline $\begin{array}{l}\text { УОС, } \\
\text { мл }\end{array}$ & $\frac{60,4( \pm 5,7)}{61,1( \pm 6,0)}$ & $\frac{63,5( \pm 4,9)}{63,0( \pm 4,2)}$ & $>0,05$ & $>0,05$ & $+1,2$ & $-0,8$ \\
\hline $\begin{array}{l}\text { МОС, } \\
\text { л/мин }\end{array}$ & $\frac{4,2( \pm 0,8)}{4,2( \pm 0,9)}$ & $\frac{4,4( \pm 0,7)}{4,3( \pm 0,8)}$ & 1,000 & $>0,05$ & 0,0 & $-2,3$ \\
\hline $\begin{array}{l}\text { ИРС, } \\
\text { Отн. ед. }\end{array}$ & $\frac{99,7( \pm 2,2)}{88,4( \pm 1,6)}$ & $\frac{96,3( \pm 2,1)}{90,9( \pm 1,8)}$ & $<0,001$ & $\mathbf{0 , 0 3 9}$ & $-11,3$ & $-5,6$ \\
\hline $\begin{array}{l}\text { ОПСС, } \\
\text { динхсхсм/-5 }\end{array}$ & $\frac{1769,5( \pm 128,8)}{1552,4( \pm 131,3)}$ & $\frac{1719,4( \pm 138,1)}{1663,9( \pm 140,9)}$ & $<0,001$ & $>0,05$ & $-12,3$ & $-3,2$ \\
\hline
\end{tabular}


Об этом свидетельствуют практически все изученные нами показатели. Так, у представителей 1-й группы имело место снижение систолического, диастолического и среднегемодинамического АД и ОПСС соответственно на 8,9 \% ( $p=0,009), 8,6 \%(p=0,025)$ $8,7 \%(p=0,046)$ и $12,3 \%(p<0,001)$. В сравниваемой группе достоверности изменений вышеназванных показателей не наблюдалось. Представляет интерес уменьшение ИРС в обеих группах обследуемых. Динамики ЧСС и МОС после СКЛ не отмечено как в 1-й, так и во 2-й группах больных.

Заключение. Таким образом, лучшие непосредственные результаты курортной терапии у больных АГ, оцениваемые по гемодинамическим показателям, выраженности клинических проявлений заболевания и параметрам качества жизни, оказались выше в группе пациентов, которым СКЛ было назначено с помощью математического моделирования. Санаторно-курортное лечение способствует снижению АД, периферического сосудистого сопротивления и

\section{Аитература}

1. Абрамович, С. Г. Особенности геропротекторного действия магнитотерапии у пожилых больных с сочетанной сердечно-сосудистой патологией / С. Г. Абрамович, А. А. Федотченко, А. В. Корякина // Вопрось курортологии, физиотерапии и лечебной физкультуры. - 1999. - № 5. - С. 7-9.

2. Абрамович, С. Г. Показатели качества жизни и индекс массы тела у больных гипертонической болезнью пожилого возраста / С. Г. Абрамович // Клиническая медицина. - 2004. - № 6 (82). - С. 27-29.

3. Абрамович, С. Г. Санаторно-курортное лечение больных артериальной гипертонией: фокус на персонализированную физиотерапию / С. Г. Абрамович, А. Г. Куликов, И. М. Михалевич, А. Г. Долбилкин // Забайкальский медицинский вестник. - 2016. - № 2. С. $10-16$.

4. Абрамович, С. Г. Способ выбора тактики санаторно-курортного лечения больных артериальной гипертонией / С. Г. Абрамович, И. М. Михалевич, А. Ю. Долбилкин // Патент РФ. Заявка № 2016105676. Приоритет от 18.02.2016 г.

5. Дзизинский, А. А. Состояние микроциркуляции и центральной гемодинамики у больных гипертонической

\section{References}

1. Abramovich S. G., Fedotchenko A. A., Koryakina A. V. Voprosyi kurortologii, fizioterapii i lechebnoy fizkulturyi. Issues of balneology, physiotherapy and physical therapy. 1999;5:7-9.

2. Abramovich S. G. Klinicheskaya meditsina. - Clinical medicine. 2004;6(82):27-29.

3. Abramovich S. G., Kulikov A. G., Mikhalevich I. M., Dolbilkin A. G. Zabaykalskiy meditsinskiy vestnik. Zabaikal'skii Medical Gazette. 2016:2:10-16.

4. Abramovich S. G., Mikhalevich I. M., Dolbilkin A. Yu. Sposob vyibora taktiki sanatorno-kurortnogo lecheniya bolnyih arterialnoy gipertoniey. Patent RF. Zayavka № 2016105676. Prioritet ot 18.02.2016.

5. Dzizinsky A. A., Abramovich S. G., Fedotchenko A. A. Voprosyi kurortologii, fizioterapii i lechebnoy fizkulturyi. - повышает уровень качества жизни пациентов АГ за счёт влияния на физический компонент здоровья.

Полученные данные явились подтверждением правильности предложенных нами формул линейных дискриминантных функций. Благодаря их использованию можно более обоснованно назначать «интенсивные» технологии СКЛ, когда наряду с бальнеотерапией хлоридными натриевыми минеральными ваннами могут быть применены аппаратные методы физиотерапии, включающие процедуры общей или трансцеребральной магнитотерапии. Включение в традиционное санаторно-курортное лечение больных артериальной гипертонией комплексной магнитотерапии способствует повышению эффективности восстановительного лечения, нормализации клинико-функциональных показателей и улучшению качества их жизни.

Определение тактики для протекания санаторного лечения целесообразно вести с применением математического моделирования, что способствует оптимизации физических методов лечения.

болезнью при лечении хлоридными натриевыми ваннами / А. А. Дзизинский, С. Г. Абрамович, А. А. Федотченко // Вопросы курортологии, физиотерапии и лечебной физкультуры. - 1987. - № 3. - С. 21-24.

6. Михалевич, И. М. Дискриминантный анализ в медикобиологических исследованиях (с применением пакета прикладных программ STATISTICA 6.1) / И. М. Михалевич, Т. Н. Юрьева. - Иркутск : РИО ГБОУ ДПО ИГМАПО, 2015. - C. 44.

7. Оганов, Р. Г. Эпидемиология артериальной гипертонии в России. Результаты федерального мониторинга 2003-2010 гг. / Р. Г. Оганов // Кардиоваскулярная терапия и профилактика. - 2011. - № 1. - С. 8-12.

8. Чазова, И. Е. Распространенность Факторов риска развития сердечно-сосудистых заболеваний в российской популяции больных артериальной гипертонией / И. Е. Чазова // Кардиология. - 2014. - № 10. C. 4-12.

9. Чазова, И. Е. Диагностика и лечение артериальной гипертонии. Клинические рекомендации / И. Е. Чазова, Е. В. Ощепкова, Ю. В. Жернакова // Кардиологический вестник. - 2015. - № 1. - С. 3-30.

Issues of balneology, physiotherapy and physical therapy. 1987;3:21-24.

6. Mikhalevich I. M., Yureva T. N. Diskriminantnyiy analiz v mediko-biologicheskih issledovaniyah (s primeneniem paketa prikladnyih programm STATISTICA 6.1). Irkutsk: «RIO GBOU DPO IGMAPO», 2015.

7. Oganov R. G. Kardiovaskulyarnaya terapiya i profilaktika. Cardiovascular therapy and prevention. 2011;1:8-12.

8. Chazova I. E. Kardiologiya. - Cardiology. 2014;10:4-12.

9. Chazova I. E., Oshchepkova E. V., Zhernakova Yu. V. Kardiologicheskiy vestnik. - Cardiology Gazette. 2015;1:3-30.

\section{Сведения об авторах:}

Абрамович Станислав Григорьевич, доктор медицинских наук, профессор, заведующий кафедрой физиотерапии и курортологии; тел.: 89025613540; e-mail: prof.Abramovich@yandex.ru

Дробышев Виктор Анатольевич, доктор медицинских наук, профессор кафедры госпитальной медицины и медицинской реабилитации; тел.: 89139130857; e-mail: doctorvik@yandex.ru 